\title{
ISOLAMENTO DE ENTEROBACTÉRIAS A PARTIR DE FRANGOS DE CORTE NECROPSIADOS: RELATO DE CASO
}

\author{
Phelipe Magalhães Duarte, Vivian Tallita Pinheiro de Santana \\ Universidade de Cuiabá - UNIC, Cuiabá, MT. E-mail: duarte.phe@gmail.com
}

\begin{abstract}
RESUMO
A bactéria patogênica Escherichia coli (E. coli) é responsável por ocasionar problemas de saúde em animais de produção, dentre estes, a colibacilose aviária. Esta doença apresenta causas multifatoriais, manifestando doença crônica respiratória, onfalite, salpingite, septicemia, peritonite, síndrome da cabeça inchada, enterites e celulite. O presente estudo buscou relatar achados clínicos de três aves de criadouro da cidade de Primavera do Leste, MT, Brasil, necropsiadas para a avaliação anatomopatológica e isolamento dos agentes causadores. A avaliação constatou necrose hepática, presença de secreção catarral na porção medial da traqueia, além de celulite com evolução para abscesso. Ao exame microbiológico, as amostras testadas resultaram positivas para o isolamento de bactérias Gram-negativas fermentadoras de lactose, caracterizadas como enterobactérias, dentre elas E. coli

Palavras-chave: Escherichia coli, Enterobactérias, Celulite, Abcesso, Enterite.
\end{abstract}

\section{ISOLATION OF ENTEROBACTERIA FROM NECROPSIED BROILERS: A CASE REPORT}

\begin{abstract}
The pathogenic bacterium Escherichia coli (E. coli) cause health problems to production animals, i.e. avian colibacillosis. This disease presents multifactorial causes, manifesting chronic respiratory disease, omphalitis, salpingitis, septicemia, peritonitis, swollen head syndrome, enteritis, and cellulitis. The present study aimed to report clinical findings of three birds from a breeder at Primavera do Leste, MT, Brazil, necropsied to the anatomopathological analysis and isolation of the causative agents. The analysis identified hepatic necrosis, presence of catarrhal secretion to the medial portion of trachea, and cellulitis with evolution to abscess. Microbiological tests resulted to the isolation of lactose-fermentive Gramnegative bacteria, characterized as enterobacteria, i.e. E. coli.
\end{abstract}

Keywords: Escherichia coli, Enterobacteria, Cellulitis, Abscess, Enteritis.

\section{INTRODUÇÃO}

A bactéria Escherichia coli (E. coli) por muito tempo foi considerada não patogênica, devido a esta fazer parte da microbiota do organismo e impedir a colonização de outros micro-organismos patogênicos ${ }^{1}$. Porém, estudos focando na estrutura genética da bactéria, bem como de seus mecanismos de aquisição de genes de virulência e resistência, permitiram o desenvolvimento de pesquisas relacionadas às infecções diarreiogênicas e extra-intestinais, assim como ampliação do conhecimento científico destas infecções ${ }^{2}$.

A infecção por $E$. coli é considerada secundária a outros agentes, sendo que a manifestação da doença é extraintestinal ${ }^{3}$. As cepas que causam lesões fora do trato intestinal são chamadas de E. coli patogênicas extraintestinais (ExPEC) ${ }^{4}$ e são responsáveis por causar colibacilose em aves (Avian Pathogenic E. 
coli - APEC) e outros animais de produção ${ }^{3}$. A colibacilose aviária apresenta alta morbidade das aves afetadas devido aos frequentes quadros de septicemia ${ }^{5}$. A suscetibilidade e a severidade da doença são maiores em aves mais jovens, porém pode acometer as aves de diferentes idades ${ }^{6}$.

A ocorrência de APEC pode levar a quadros de colisepticemia, peritonite, pleuropneumonia, celulite, coligranuloma, doença respiratória crônica (DCR) complicada, onfalite, síndrome da cabeça inchada, panoftalmia, e ooforite ${ }^{3,7,8}$. Na avaliação anatomopatológica, pode-se constatar ainda pneumonia, esplenomegalia, fígado esverdeado, aerossaculite, pericardite, enterite, peritonite, salpingite, meningoencefalite, panoftalmite, osteomielite, sinovite e congestão de tecido muscular $^{3,9}$.

A manifestação e disseminação da $E$. coli entre as aves de corte estão relacionadas à condições de manejo, como superlotação de animais, alta densidade populacional, temperatura ambiental elevada, co-infecções, imunossupressão, além de ventilação deficiente e com altos níveis de amônia e poeira no ambiente, o que lesiona o epitélio ciliar da traqueia e possibilita a colonização na mucosa do trato respiratório ${ }^{10}$. Sinais clínicos inespecíficos como sonolência, prostração, baixo consumo de ração e ganho de peso, baixa uniformidade, aumento da refugagem no lote e diarreia, consequentemente geram prejuízos econômicos devido ao aumento de mortalidade e baixa produtividade ${ }^{6}$. De acordo com Ferreira et al. ${ }^{11}$ e Sesterhenn et al. $^{12}$, a colibacilose aviária representa uma das principais causas de condenação de carcaça em frigoríficos de frangos de corte, sendo considerada uma patologia emergente na avicultura mundial ${ }^{13}$. Portanto, a bactéria E. coli constitui um importante agente infeccioso que pode gerar prejuízos econômicos ao comprometer a produtividade do setor da avicultura brasileira ${ }^{14}$.

Dentre as enterobactérias causadoras de importantes enfermidades para as aves também estão as Salmonellas ${ }^{15}$. A Salmonella enterica sorovar Pullorum é responsável pelos casos de Pulorose $^{16}$, com maior susceptibilidade em aves jovens de até três semanas de idade $^{17}$, e a Salmonella Gallinarium é a causadora do Tifo aviário $^{16}$, comumente registrado em aves adultas mas, altamente patogênico à todas idades ${ }^{18,19}$.

No Brasil, estudos têm correlacionado as lesões macroscópicas de causa infeciosas e a caracterização histológica com o isolamento do agente presente nos órgãos afetados. Tais pesquisas têm fundamental importância para avaliação do impacto dos agentes infecciosos como causa de condenação da produção em abatedouros de frango de corte ${ }^{20}$.

Diante do exposto, o presente estudo buscou relatar os achados clínicos de aves de criadouro da região de Primavera do Leste, MT, Brasil, necropsiadas para a avaliação anatomopatológica e isolamento dos agentes causadores.

\section{METODOLOGIA}

Três frangos de corte (Gallus gallus domesticus) (duas fêmeas e um macho) oriundos de criatório da cidade Primavera do Leste, MT, Brasil, com plantel de 100 aves aproximadamente, foram encaminhadas para necropsia e avaliação anatomopatológica junto ao Laboratório de Anatomia da Universidade de Cuiabá (UNIC, Campus de Primavera do Leste). O plantel apresentou histórico clínico de emagrecimento constante e progressivo, com evolução para caquexia, e agravado pela apatia e diminuição do consumo de alimento. Casos de sintomatologia respiratória como dificuldade respiratória e rouquidão também foram relatados na mesma propriedade. Alguns animais apresentaram quadro de infertilidade, e no caso específico das fêmeas, ovos malformados e pintinhos com deficiências congênitas. De forma mais frequente, os animais desenvolveram quadros diarreicos, com fezes muco-aquosas, fétidos e de coloração marrom até enegrecido. Os animais de raça caipira, e também índio gigante, haviam sido submetidos a tratamento e profilaxia antiparasitária recente.

O exame microbiológico foi realizado a partir do cultivo de amostras coletadas das alterações observadas na avaliação anatomopatológica durante a necropsia. Assim, as amostras foram coletadas do interior da celulite, fígado, secreção traqueal, conteúdo intestinal, baço e coração com o auxílio de swab estéril. $O$ material coletado foi semeado em ágar Nutriente e incubado em estufa a $37^{\circ} \mathrm{C}$ por $48 \mathrm{~h}$. Após o desenvolvimento das colônias presentes em ágar Nutriente, foi realizada coloração de Gram. Posteriormente, selecionadas as colônias que apresentaram maior crescimento bacteriano para semear as placas contendo os seguintes meios de cultura: ágar Cled, ágar MacConkey, e Caldo verde-bile-brilhante-2\%. Estes, após serem 
semeados, foram incubados em estufa a $37^{\circ} \mathrm{C}$ por $72 \mathrm{~h}$.

\section{RESULTADOS E DISCUSSÃO}

O Teste de coloração de Gram identificou a presença de bactérias Gram-negativas no material amostrado durante a necropsia. Dentre as Gram-negativas relacionadas às enfermidades de aves estão $E$. coli e Salmonella.

A infeção por $E$. coli patogênica pode ocasionar a colibacilose aviária que é caracterizada pela presença de sinais clínicos de infecção localizada ou sistêmica ${ }^{8,10,21}$, dentre eles alguns inespecíficos, o que aumenta a importância da avaliação de aspectos como a caquexia entre outras alterações reportadas pelo proprietário do plantel quanto aos aspectos comportamentais, hábitos alimentares, dentre outros.

Nas infecções por Salmonella, as aves podem desenvolver sintomas como sonolência, perda de apetite, diarreia branca até brancaamarelada, asas caídas e morte por infecção com Salmonella enterica sorovar Pullorum, caracterizando a doença denominada pulorose ${ }^{16}$. $\mathrm{Em}$ estudo conduzido por Oliveira et al. ${ }^{22}$ foram observados sinais clínicos em experimento com aves adultas infectadas com tifo aviário (Salmonella sorova Gallinarium) como diarréia amarelada/verde com início 2-4 dias após a infecção. Além disso, segundo FREITAS NETO et al. ${ }^{23}$, podem ocorrer outros sintomas característicos de tifo aviário como depressão, prostração, anorexia, asas caídas, penas eriçadas, e cloaca suja.

Durante a necropsia, as alterações anatomopatológicas mais evidentes foram observadas no fígado, condizentes com necrose hepática focalizada. De acordo com Maclachlan e Cullen $^{24}$ e Ron ${ }^{25}$ a infecção do fígado e a subsequente inflamação no órgão podem ser primárias, ou fazer parte de um processo sistêmico. Nos casos de colibacilose aviária podem ocorrer alterações hepáticas que se apresentam de forma difusa e afetam as membranas internas da cavidade celômica, acarretando em condenação total da carcaça, o que, consequentemente, gera grandes perdas econômicas para a criação ${ }^{26}$. No caso do tifo pode-se observar lesões hepáticas e também cardíacas ou renais, como necrose multifocal, degeneração vacuolar e reação inflamatória com infiltração polimorfa no rim de aves semipesadas $^{23}$. Achados anatomopatológicos em animais acometidos com pulorose como hepatomegalia com necrose focal, além de coloração esverdeada ou bronze neste órgão, folículos hemorrágicos, deformados e pálidos com leve hemorragia, enterite catarral ou hemorrágica nos intestinos, petéquias hemorrágicas no coração foram apontados em necropsia ${ }^{27-29}$.

Adicionalmente, todas as aves estudadas apresentaram áreas necróticas no fígado, de coloração esverdeada, corroborando com o observado por Dey et al. ${ }^{30}$, que também observou colangio-hepatite heterofílica multifocal, seguida de hepatite necrosante aleatória, como os sinais clínicos de maior incidência. Casagrande et al. ${ }^{20}$ também registraram a ocorrência de alterações macroscópicas hepáticas (manchas esverdeadas) em frangos de corte condenados por colibacilose, assim como observado no presente estudo. Silva et al. ${ }^{31}$ isolaram $E$. coli em tecido hepático, com coloração esverdeada, de frangos provenientes de matadouros avícolas.

Achados no trato respiratório também foram assinalados, como a presença de secreção catarral na porção medial da traqueia, e celulite na região do peito de uma das aves estudadas, que evoluiu para um abcesso intramuscular de aspecto purulento. Em aves, a ocorrência de celulite pode estar associada à infecção bacteriana, constituindo uma inflamação aguda, supurativa e difusa que afeta os tecidos subcutâneos e pode atingir o tecido muscular, além de estar frequentemente associada à formação de abscessos ${ }^{13}$. E. coli patogênica é o microrganismo responsável em lesões como estas $^{24-26}$

E. coli é um microrganismo encontrado normalmente na microbiota intestinal de aves sadias vivendo comensalmente. Porém, as amostras patogênicas se instalam, podendo se multiplicar e desenvolver a afecção ${ }^{33}$. A confirmação do diagnóstico é realizada pelo isolamento e identificação de amostras patogênicas para aves ${ }^{3}$, as quais crescem rapidamente em meios bacteriológicos simples ${ }^{34}$.

De acordo com Albuquerque et al. $^{35}$, a escolha de diversos meios de cultura é um prérequisito essencial para o cultivo de microrganismos. Para o desenvolvimento do presente estudo utilizou-se o ágar MacConkey, que resultou na formação de em colônias arroxeadas, o ágar Cled e Caldo verde bile brilhante $2 \%$, que resultaram em modificação da coloração do ágar para amarela e formação de 
bolhas de gás, respectivamente. Assim, os resultados dos testes bacteriológicos permitem sugerir o desenvolvimento de colônias E.coli cultivada a partir das amostras obtidas por necropsia. Gyles et al. ${ }^{34}$ confirmam a formação de colônias de coloração roxa cultivadas a partir de tecidos colhidos durante a necropsia e isoladas em meio de seletivo de ágar MacConkey, assim como registrado para o presente estudo.

Segundo Brasil $^{36}$, a característica de crescimento de espécies de Salmonella em ágar Cled são de colônias planas de coloração azul, resultando na interpretação de colônias lactose negativa, diferente do registrado nesta pesquisa, em que as colônias desenvolvidas apresentaram coloração amarelada. Segundo Roitman ${ }^{37}$, as salmonelas são bacilos móveis, Gram-negativos, que caracteristicamente, não fermentam lactose.

No trabalho de Silva et al. ${ }^{31}$, os autores incubaram colônias suspeitas de $E$. coli preparadas a partir de amostras do fígado de frangos de abate, e estas ao se desenvolverem apresentaram características típicas dessa bactéria (colônias rosas-avermelhadas, lactose positivas), assim como encontrado para o presente estudo.

Desta forma, a ocorrência de crescimento microbiológico em ágar seletivo para enterobactérias Gram-negativas lactose positivas, acrescido dos achados anatomopatológicos, permite inferir o possível isolamento de enterobactérias, tal como $E$. coli. O que também possibilita sugerir que o quadro clínico dos frangos de corte no plantel estudado possa estar relacionado à infecção por $E$. coli, e, portanto, sugestiva de colibacilose, sendo necessária a realização de testes bioquímicos para a identificação específicas da bactéria.

Por fim, deve-se ressaltar a importância de controle sanitário e de boas práticas de manejo, assim como e estudos microbiológicos periódicos para a garantia da sanidade animal e humana, com relação a exposição durante o consumo desses animais.

\section{CONFLITO DE INTERESSES}

Os autores declaram não haver qualquer potencial conflito de interesse que possa interferir na imparcialidade deste trabalho científico.

\section{REFERÊNCIAS}

1. Machado LS, Nascimento ER, Almeida DO, Pereira VL a., Abreu DLC, Gouvêa R, et al. PCR na deteç̧ão de gene FEL A de Escherichia coli em frangos de corte. Arq Inst Biol. 2013;80(2):145-9. https://doi.org/10.1590/S1808-

$\underline{16572013000200002}$

2. Kawakami AP, Osugui L, César AT, Waisse $S$, Carvalho VM De, Bonamin LV, et al. In vitro growth of uropathogenic Escherichia coli isolated from a snow leopard treated with homeopathic and isopathic remedies: a pilot study. Int J High Dilution Res. 2009;8(27):41-4.

3. Ferreira A, Knobl T. Colibacilose. In: Junior $A$, Silva E, Fábio J, Sest i L, Zuanaze $M$, organizadores. Doença das aves. 2.ed . Campinas: Fundação APINCO; 2009. p. 457-71.

4. Almeida AMS, Leonídio ARA, Andrade MA. Associação dos quadros anatomopatológicos de colibacilose aviaria com genes de virulência de Escherichia coli. Vet Foco. 2016;13(2):113-31.

5. Cardoso ALSP, Tessari ENC, Castro AGM, Zanatta GF. Avaliação da susceptibilidade a antimicrobianos de cepas de Escherichia coli de origem aviária. Arq Inst Biol. 2002;69(2):1-5.

6. Campos L, Trabulsi L. Escherichia. In: Trabulsi L, Alterthum F, Gompertz O, Candeias JAN, organizadores. Microbiologia. 3.ed Atheneu; 1999.

7. Gross W. Diseases due to E. coli in Poultry. In: Gyles C. (Org.). Escherichia coli indomestic animals and humans. Oxon: $C A B$ International; 1994. p.237-59.

8. Barnes $\mathrm{H}$, Nolan L, Vaillancourt J. Colibacillosis. In: Saif Y, Fadly A, Glisson J, McDougald L, Nolan L, Swayne D (Org.). Disease of Poultry. Blackwell Publishing, Ames; 2008. p.691-737.

9. Barnes H, Gross W. Collibacillosis. In: Calnek B, Barnes H, Beard C, McDougald L, Saif Y (Org.). Diseases of poultry. lowa: The lowa State University Press; 1997. p.131-41.

10. Lutful Kabir SM. Avian colibacillosis and salmonellosis: A closer look at epidemiology, pathogenesis, diagnosis, control and public health concerns. Int J Environ Res Public Health. 2010;7(1):89-114.

https://doi.org/10.3390/ijerph7010089 
11. Ferreira TZ, Sesterhenn R, Kindlein L. Perdas econômicas das principais causas de condenações de carcaças de frangos de corte em Matadouros-Frigorífi cos sob Inspeção Federal no Rio Grande do Sul , Brasil. Acta Sci Vet. 2012;40:1-6.

12. Sesterhenn R, Ferreira TZ, Kindlein L, Moraes HLS. Impacto econômico de condições post mortem de aves sob inspeção estadual no estado do Rio Grande do Sul. Alim Bioen Bras Mundo. 2010;210:1-3.

13. Brito BG, Tagliari KC. Celulite aviária por Escherichia coli. UNOPAR Cient Ciên BiolSaúde. 2000;2(1):143-9.

14. Roberta L, Camargo P, Suffredini IB. Impacto causado por Escherichia coli na produção de animais de corte no Brasil: revisão de literatura. J Heal Sci Inst. 2015;33(2):193-7.

15. Shah DH, Lee M, Park J, Lee J, Eo S, Kwon J, et al. Identification of Salmonella Gallinarum virulence genes in a chicken infection model using PCR-based signature-tagged mutagenesis Identification of Salmonella gallinarum virulence genes in a chicken infection model using PCRbased signature-tagged mutagen. Mirobiology. 2005;151:3957-68.

https://doi.org/10.1099/mic.0.28126-0

16. Berchieri Junior Â. Salmoneloses aviárias. In: Berchieri Junior Â, Macari M (Org.). Doenças das aves. Campinas: FACTA; 2000. p.185-96.

17. Saif $Y$, Fadly A, Glisson J, McDougald L, NolaN L, Swayne D. Diseases of Poultry. 12 Revised. Arnes, Al, United States: lowa State University Press; 2008. 1352p.

18. Berchieri A. J, Murphy CK, Marston K, Barrow PA. Observations on the persistence and vertical transmission of Salmonella enterica serovars Pullorum and Gallinarum in chickens: Effect of bacterial and host genetic background. Avian Pathol. 2001;30(3):221-31. https://doi.org/10.1080/03079450120054631

19. Pomeroy BS, Nagaraja K V. Fowl typhoid. In: Calnek BW, Barnes HJ, Beard CW, Reid WM, Yoder HW (Org.). Poultry Disease. Ames: lowa State University Press; 1991. p.87-98.

20. Casagrande RA, Machado G, Guerra PR,
Castro LA, Spanamberg A, Silva SC, et al. Caracterização anatomopatológica e bacteriológica em frangos de corte condenados totalmente por colibacilose sob Serviço de Inspeção Federal. Pesqui Vet Bras. 2017;37(9):949-57.

https://doi.org/10.1590/s0100736×2017000900009

21. Jansen $T$, Schwarz $C$, Preikschat $P$, Voss $M$, Philipp H-C, Wieler LH. Virulence-associated genes in avian pathogenic Escherichia coli (APEC) isolated from internal organs of poultry having died from colibacillosis. Int J Med Microbiol. 2001;291(5):371-8. https://doi.org/10.1078/14384221-00143

22. Oliveira $G H$ De, Junior $A B$, Fernandes $A C$. Experimental infection of laying hens with Salmonella enterica sorovar Gallinarum. 2005;51$6 . \quad$ https://doi.org/10.1590/S1517$\underline{83822005000100011}$

23. Freitas Neto O, Arroyave $W$, Alessi A, Fagliari $\mathrm{J}$, Berchieri A. Infection of commercial laying hens with Salmonella Gallinarum: clinical, anatomopathological and haematological studies. Rev Bras Ciên Avícola. 2007;9(2):133-41. https://doi.org/10.1590/S1516$\underline{635 \times 2007000200010}$

24. Maclachlan N, Cullen J. Fígado, sistema biliar e pâncreas exócrino. In: Carlton W (Org.). Patologia Veterinária Especial de Thomson. 2.ed Porto Alegre: Artmed; 1998. p.265-98.

25. Ron EZ. Host specificity of septicemic Escherichia coli: human and avian pathogens. Curr Opin Microbiol. 2006;9(1):28-32. https://doi.org/10.1016/j.mib.2005.12.001

26. Oliveira FR, Machado FME, Coelho E. Estudo anatomopatológico de fígados que levam a condenação total de carcaça, na linha de inspeção, durante o abate de frangos de corte (Gallus gallus domesticus) na região do Triângulo Mineiro. PUBVET. 2014;8(2):ed. 251, art. 1662. Disponível em: https://www.researchgate.net/publication/3094 70311_Estudo_anatomopatologico_de_figados_q ue_levam_a_condenacao_total_de_carcaca_na_I inha_de_inspecao_durante_o_abate_de_frangos _de_corte_Gallus_gallus_domesticus_na_regiao_ do_Triangulo_Mineiro.

https://doi.org/10.22256/pubvet.v8n2.1662 
27. Rahman. MA, Samad MA, Rahman MB, Kair AML. Bacterio-pathological studies on salmonellosis, collibacillosis and pasteurellosis in natural and experimental infections in chickens. Bangladesh J Vet Med. 2004;2(1):1-8. https://doi.org/10.3329/bjvm.v2i1.1926

28. Hossain $M$, Chowdhury $E$, Islam M, Haider M, Hossain M. Avian Salmonella Infection: Isolation and Identification of Organisms and Histopathological Study. Bangladesh J Vet Med. 2006;4(1):7-12.

https://doi.org/10.3329/bjvm.v4i1.1518

29. Islam $M$, Haider $M$, Chowdhury $E$, Kamruzzaman M, Hossain M. Seroprevalence and pathological study of Salmonella infections in layer chickens and isolation and identification of causal agents. Bangladesh J Vet Med. 2006;4(2):79-85.

https://doi.org/10.3329/bjvm.v4i2.1288

30. Dey B, Chen Y, Hsieh C, Chan D. Detection of septicemia in chicken livers by spectroscopy. Poult Sci. 2003;82(2):199-206. https://doi.org/10.1093/ps/82.2.199

31. Matos I, Tannus L, Verônica É, Almeida V, Mendes R. Presença de Escherichia coli em fígados de frangos provenientes de matadouros avícolas. Rev Bras Saúde Prod Anim. 2012;13(3):694-700.

https://doi.org/10.1590/S1519$\underline{99402012000300009}$

32. Fallavena $L$, Moraes $H$, Salle $C$, Silva A da, RS $\mathrm{V}$, Nascimento $\mathrm{V}$ do, et al. Diagnosis of skin lesions in condenninned or downeraded broi ler carcasses-amicroscopic and macroscopie study. Avian Pathol. 2000;29:557-62. https://doi.org/10.1080/03079450020016797

33. Bettelheim K. Escherichia coli in the normal flora of humans and animals. In: Sussman M (Org.). Escherichia coli mechanisms of virulence. 1.ed Cambridge University Press; 1997. p. 85-109.

34. Gyles C, Prescott J, Songer J, Thoen O. Pathogenesis of bacterial infections in animals. Vol.4. Blackwell Publishing; 2010. 265p. https://doi.org/10.1002/9780470958209

35. Albuquerque R de, Ito NMK, Miyaji $\mathrm{Cl}$. Estudo comparativo de diferentes meios de cultura para o isolamento de salmonelas em matérias-primas e rações. Braz J Vet Res Anim Sci. 2000;37(1):3443. https://doi.org/10.1590/S1413$\underline{95962000000100012}$

36. Brasil. Microbiologia Clínica para o Controle de Infecções relacionadas à Assistência à Saúde. In: Módulo 5: Tecnologia em Serviços de Saúde: Descrição dos Meios de Cultura Empregados nos Exames Microbiológicos. 1.ed Brasília: ANVISA; 2013. p.95.

37. Roitmam I, Travassos LR, Azevedo JL. Tratado de Microbiologia. v.2. São Paulo: Manole LTDA; 1991. 